Saudi Journal of Medical and Pharmaceutical Sciences

Abbreviated Key Title: Saudi J Med Pharm Sci ISSN 2413-4929 (Print) |ISSN 2413-4910 (Online) Scholars Middle East Publishers, Dubai, United Arab Emirates Journal homepage: https://saudijournals.com/sjmps

\title{
Body Burden of Lead, Cadmium and Vanadium among HIV Patients on Antiretroviral Drugs in Port Harcourt, Niger Delta, Nigeria
}

Ifeyinwa Chijioke- Nwauche*, Sydney Yakubu, Ndidiamaka Obasi, Sordum Nboi

Department of Clinical Pharmacy and Management, Faculty of Pharmaceutical Sciences, University of Port Harcourt, Port Harcourt, Nigeria

DOI: $10.36348 /$ sjmps.2020.v06i11.005 $\quad$ | Received: 07.10.2020 | Accepted: 21.10 .2020 | Published: 13.11 .2020

*Corresponding author: Ifeyinwa Chijioke-Nwauche. $\mathrm{PhD}$

Abstract

Background: Exposure to environmental heavy metals predispose humans to health risks and hazards. Increased risks of chronic diseases have been attributed to increased exposure to heavy metals. Studies have linked early onset of chronic diseases in HIV-infected persons to exposure to heavy metals in the environment. Given the massive industrialization and crude oil exploration in the Niger Delta, there is huge environmental pollution in the area. Objectives: The study sought to evaluate the presence of blood lead, cadmium and vanadium (notable heavy metals associated with crude oil exploration) levels of HIV-positive and HIV-negative volunteers in Port Harcourt, Niger Delta Nigeria. Materials and Methods: The study evaluated the presence of lead, cadmium and vanadium in HIV-positive and HIV-negative volunteers in Port Harcourt, Nigeria. Blood samples of a total of 100 subjects (60 HIV-positive and 40 HIV-negative subjects) with age range 15->60 years were analysed using Solar Thermo Elemental Flame Absorption Spectrometer (S4 710). Results: Mean blood levels of lead, Cadmium and Vanadium obtained were $2.00 \pm 6.25 ; 1.70 \pm 11.20$ and $0.03 \pm 0.04$ ppm respectively for HIV-subjects and 0.15 $\pm 0.28,0.04 \pm 0.05,0.01 \pm 0.02$ ppm for HIV-negative subjects. Conclusions: This study demonstrated that HIV-positive subjects had significantly higher levels of all the heavy metals compared to HIV-negative persons thereby predisposing them to be more at risks of the metals.

Keywords: lead, cadmium, vanadium, exposure, HIV, blood.

Copyright () 2020 The Author(s): This is an open-access article distributed under the terms of the Creative Commons Attribution 4.0 International License (CC BY-NC 4.0) which permits unrestricted use, distribution, and reproduction in any medium for non-commercial use provided the original author and source are credited.

\section{INTRODUCTION}

HIV infection still remains a major public health concern globally especially in sub-Saharan Africa. Nigeria has the highest number of new infections and as at 2015, bears the second highest burden of HIV globally with an estimated number of about 3.2 million people living with HIV [1]. The current national prevalence is $1.4 \%$ declining from a previous value of $4.1 \%$ with 1.9 million people living with HIV/AIDS [2]. Rivers State, Nigeria ranks third with a prevalence of $3.8 \%$ [3]. The introduction of antiretroviral drugs for the treatment of HIV infection changed the whole course of HIV/AIDS disease and management such that many infected people now live for extended period hence making HIV infection a chronic disease. Antiretroviral therapy (ART) are generally classified into first, second and third lines with the choice of regimen dependent among other things on potency, safety and interactions with other medicines [4]. With the improved management of HIV persons, non-communicable diseases have become emerging health problems among this population [5]. Amongst the chronic diseases that have proven to be of significant concern in HIV-infected persons are diabetes, cardiovascular diseases, hypertension, renal failure and HIV-related malignancies, ${ }^{5}$ with some of the comorbidities accounting for over 50\% of deaths occurring in these group of persons on Antiretroviral therapy (ART) $[6,7]$. A study of the determinants of these chronic diseases in this population is therefore very important.

Environmental heavy metals predispose humans to several health risks and hazards [8]. Studies have linked early onset of chronic diseases in HIVinfected persons to exposure to heavy metals in the environment $[9,10]$. Increased risks of chronic diseases have been attributable to increased exposure to heavy metals and this could be worse for HIV-infected persons whose immunity is already compromised.

Given the massive industrialization and crude oil exploration in the Niger Delta, there is huge environmental pollution. In Nigerian cities, various environmental matrices namely air, soil and water are known to be polluted by heavy metal leading to food 
contamination. Exposure to Cadmium $(\mathrm{Cd})$ is primarily through inhalation and ingestion of fruits and vegetables due to its high rate of soil to plant transfer [11]. Environmental pollution with heavy metals is even more severe in some developing countries where the economy has been prioritized over environmental effects [12]. In his review, Orisakwe [13] highlighted the increased incidence and prevalence of some metabolic disorders that are of environmental importance in Nigeria. Unfortunately, the health implications of this heavy metal pollution are largely ignored. Heavy metals lead, Cadmium and Zinc ( $\mathrm{Pb}, \mathrm{Cd}$ and $\mathrm{Zn}$ ) have also been associated with semen quality with a significant association with increased seminal fluid among HIV-infected men in China [14]. The study sought to evaluate the presence of blood lead, cadmium and vanadium levels of HIV-positive and HIV-negative volunteers in Port Harcourt, Niger Delta Nigeria. These heavy metals been associated with crude oil exploration.

\section{Materials ANd Methods}

The study was conducted in the ARV adult clinic of University of Port Harcourt Teaching Hospital, (UPTH) Port Harcourt, Nigeria and the Lulu Brigg's Health Centre, University of Port Harcourt, Port Harcourt, Nigeria. Study population included HIVpositive persons receiving treatment at the ARV clinic of UPTH. Patients were recruited and placed on different regimens of highly active antiretroviral therapy (HAART) and were screened for adverse drug reactions. HIV-negative volunteers were recruited from the University of Port Harcourt to serve as control group. Informed consent and signed forms were obtained from each participant prior to enrolment. All aspects of this study were approved by the Ethics and Research Committees of UPTH.

Inclusion criteria for the HIV-positive persons included: HIV-positive and on antiretroviral (ARV) therapy, attending the ARV clinic in UPTH and willingness to participate. For the control group, volunteers were recruited if they met the following criteria: students who have been confirmed HIVnegative and willingness to participate.

Pretested self-administered well-structured questionnaires were used to obtain relevant information from the all participants. Data obtained included, demography inclusive of area of residency, ARV drugs as well as the regimen the patients are placed on.

Using sterile disposable syringe, $3 \mathrm{mls}$ of blood were collected by venipuncture from the participants into labelled $5 \mathrm{~mL}$ EDTA plastic bottles containing $\mathrm{K} 3 \mathrm{EDTA}$ as anticoagulant and stored in $-20^{\circ} \mathrm{C}$ freezer. Each $3 \mathrm{ml}$ sample was transferred into $100 \mathrm{~mL}$ conical flasks. Perchloric acid and nitric acid were added in the ratio $1: 3$ as follows: $2 \mathrm{~mL}$ perchloric acid $(70 \% \mathrm{v} / \mathrm{v})$ and $6 \mathrm{~mL}$ nitric acid $(72 \% \mathrm{v} / \mathrm{v})$. The conical flask was covered with an evaporating dish and the mixture digested at low temperature using a thermostated Bitinett hot plate until a clear solution is obtained. The digest was made up to $20 \mathrm{~mL}$ with deionized water in a $20 \mathrm{~mL}$ standard flask. Analysis of the sample for the heavy metals $(\mathrm{Pb}, \mathrm{Cd}, \mathrm{V})$ were carried out using Solar Thermo Elemental Flame Absorption Spectrometer (S4 710) measured at 228.8-283.3nm [15].

Data analysis was done with Statistical Package for Social Sciences (SPSS) software, version 20. Using descriptive statistics and graphical displays, data were reported as mean \pm standard deviation, unless otherwise indicated. The p-value was set at 0.05 significant level.

\section{RESUlTS}

Table 1 shows the demographic data of the participants. One hundred volunteers HIV-positive $(n=60)$ and HIV-negative $(n-40)$ participated in this study. A greater percentage $(68.3 \%)$ of the HIVpositive subjects were females. Demographic data of the test group (HIV-positive) shows the age range of participants were 20->60 years while for the control group, the range was 19-39 years (Table 1). Distribution of occupation for the test group is as follows: Business people/Traders $(65 \%)$, civil servants $(10 \%)$, self-employed $(10 \%)$, students $(8.3 \%)$ and teachers $(6.7 \%)$. All the participants from the control group were students. With regards to education, in the test group, the levels of education were $8.3 \%, 71.7 \%$ and $20.0 \%$ for primary, secondary and tertiary education respectively. All the participants reside in different areas of Port Harcourt. The test group participants receive HIV treatment from the ARV Clinic of the UPTH on different regimens as shown (Fig. 1). More than half of the participants are on the regimen lamivudine, zidovudine and nevirapine $(3 \mathrm{TC}+\mathrm{ZDV}+\mathrm{NVP})$, followed by lamivudine, abacavir and efavirenz $(3 \mathrm{TC}+\mathrm{ABC}+\mathrm{EFV})$. 
Ifeyinwa Chijioke- Nwauche et al., Saudi J Med Pharm Sci, Nov, 2020; 6(11): 698-703

Table-1: Demographic data for test and control groups.

\begin{tabular}{|c|c|c|c|c|}
\hline \multirow[b]{2}{*}{ Category } & \multicolumn{2}{|c|}{ Test Subjects } & \multicolumn{2}{|c|}{ Control Subjects } \\
\hline & Frequency & Percent & Frequency & Percent \\
\hline \multicolumn{5}{|l|}{ Gender } \\
\hline Male & 19 & 31.7 & 35 & 87.5 \\
\hline Female & 41 & 68.3 & 5 & 12.5 \\
\hline Total & 60 & 100 & 40 & 100 \\
\hline \multicolumn{5}{|l|}{ Age } \\
\hline $15-19$ & & & 19 & 47.5 \\
\hline $20-29$ & 8 & 13.3 & 18 & 45 \\
\hline $30-39$ & 20 & 33.3 & 3 & 7.5 \\
\hline $40-49$ & 20 & 33.3 & & \\
\hline $50-59$ & 10 & 16.7 & & \\
\hline$>60$ & 2 & 3.3 & & \\
\hline Total & 60 & 100 & 40 & 100 \\
\hline \multicolumn{5}{|l|}{ Religion } \\
\hline Christianity & 60 & 100 & 40 & 100 \\
\hline Total & 60 & 100 & 40 & 100 \\
\hline \multicolumn{5}{|c|}{ Marital status } \\
\hline Single & 20 & 33.3 & 40 & 100 \\
\hline Married & 39 & 65.0 & & \\
\hline Widowed & 1 & 1.7 & & \\
\hline Total & 60 & 100 & 40 & 100 \\
\hline
\end{tabular}

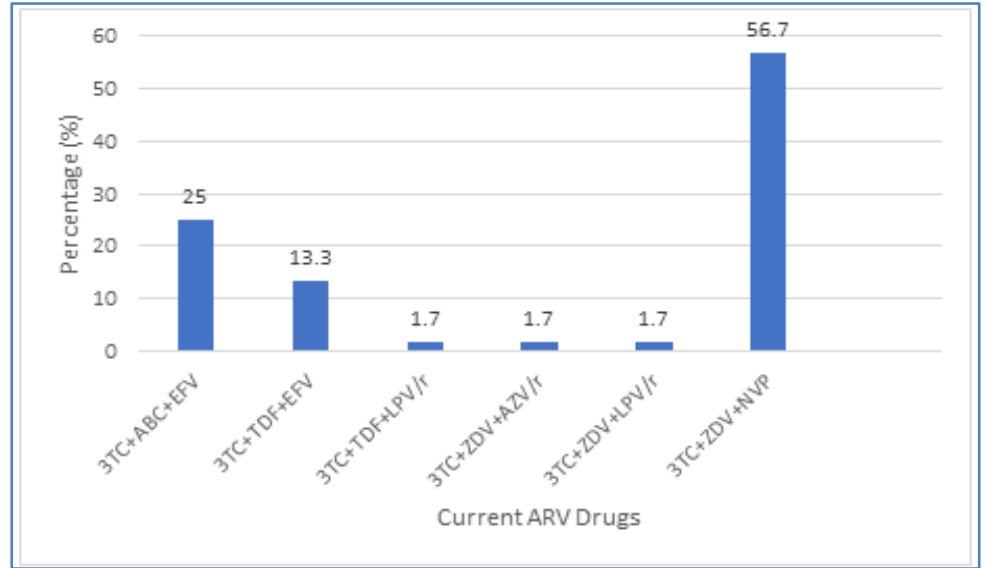

Fig-1: Distribution of ARV regimens for the test group

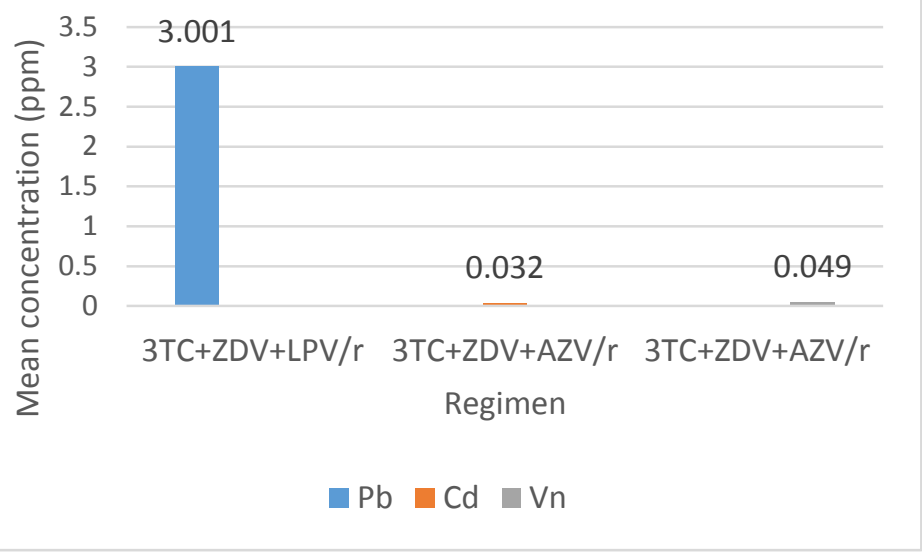

Fig- 2: Distribution of heavy metals' concentrations VS ARV regimens

Legend: $3 \mathrm{TC}=$ Lamivudine; ZDV = Zidovudine; LPV/r; Lopinavir-ritonavir; AZV/r = Atazanavir-ritonavir; TDF = Tenofovir; NVP = Nevirapine; $\mathrm{ABC}=$ Abacavir; EFV = Efavirenz 
Analysis of the results shows higher levels of all the heavy metals in the test group people compared to the control group. In all the values, there were statistically significant differences between the samples for all the metals (Table 2). A very large proportion
(48/60:80\%) of the test group had blood vanadium levels exceeding the acceptable concentration compared to the minimal $(3 / 40: 7.5 \%)$ of the control group that exceeded the limit.

Table-2: Comparison of heavy metals in the two groups

\begin{tabular}{|c|c|c|c|c|}
\hline & \multicolumn{2}{|c|}{ Concentration of heavy metals (ppm) } & p-value & Acceptable limit \\
\hline & HIV-positive $(\mathrm{n}=60)$ & HIV-negative (n-40) & & \\
\hline Lead $(\mathrm{Pb})$ & $2.00 \pm 6.25$ & $0.15 \pm 0.28$ & 0.002 & $\begin{array}{l}10 \mu \mathrm{g} / \mathrm{dl} \\
(0.1 \mathrm{ppm})\end{array}$ \\
\hline Cadmium $(\mathrm{Cd})$ & $1.70 \pm 11.20$ & $0.04 \pm 0.05$ & 0.01 & $\begin{array}{l}0.03-0.12 \mu \mathrm{g} / \mathrm{dl} \\
(0.0003-0.0012 \mathrm{ppm})\end{array}$ \\
\hline Vanadium (V) & $0.03 \pm 0.04$ & $0.01 \pm 0.02$ & 0.015 & $\begin{array}{l}0.5 \mu \mathrm{g} / \mathrm{L} \\
(0.0005 \mathrm{ppm})\end{array}$ \\
\hline
\end{tabular}

Patients on 3TC $+\mathrm{ZDV}+\mathrm{LPV} / \mathrm{r}$ regimen had the highest concentration of $\mathrm{Pb}$ in the blood. On the other hand, those on $3 \mathrm{TC}+\mathrm{ZDV}+\mathrm{AZV} / \mathrm{r}$ regimen recorded the highest concentrations of both cadmium and vanadium (Fig. 2).

\section{DisCUSSIONS}

The association between heavy metals and HIV-positive persons and the HAART has not been widely studied especially in Nigeria. Relationship of HIV infection and socio-economic status has long been established and this is reflected in the higher prevalence in poorer communities and this could possibly explain the higher exposure of this vulnerable group of persons to heavy metals [16]. Our present study was not able to establish the socio-economic status of these patients; however, National Bureau of Statistics shows that Rivers State of which Port Harcourt is the capital had an unemployment rate of $41.82 \%$ implying that 4 out of every 10 persons in the state was not doing anything. This could possibly be an influencing factor to the increased exposure of these metals.

The present study evidently shows that blood $\mathrm{Cd}$ levels in HIV-positives are higher than the permissible limit of $0.03-0.12 \mu \mathrm{g} / \mathrm{dl}$ of $\mathrm{Cd}$ equivalent to $0.0003-0.0012 \mathrm{ppm}$ [17]. This is consistent with a previous study which also reported a higher concentration of $\mathrm{Cd}$ among $\mathrm{HIV}$-infected persons compared to their HIV-negative counterparts [18]. The higher levels of the metals in the HIV-positives is in consonance with a study in the U.S that established a significant higher blood levels of $\mathrm{Pb}$ and $\mathrm{Cd}$ compared to the HIV-negative counterparts [18]. An earlier study in Benin City, Niger Delta region of Nigeria, also reported higher levels of $\mathrm{Pb}, \mathrm{Cd}, \mathrm{Hg}$ and Nickel in HIV1 infected patients than their negative counterparts [19]. The study further reported a significant higher level of $\mathrm{Cd}$ among the patients on HAART compared to the HAART-naïve subjects. The higher levels of these metals could be as a result of toxic effects of the metals on the immune system as reported by Lehman et al, and this could be more deleterious on HIV-patients who are already immunocompromised [20]. These higher levels can be contributory to the development of cardiovascular diseases among HIV-infected patients since this has been established in earlier studies [21]. Chronic cadmium exposure effects have been established to occur mainly on the kidneys, lungs and bones [22]. Earlier studies have suggested that HIV infection predisposes the patients to reduced ability to clear toxins as a result of impaired renal and liver function with subsequent impaired detoxification, thereby influencing the clearance of the metals from the body even though the exposure may be similar [23, 24].

Byrne \& Kosta reported blood vanadium levels in healthy individuals to be below $0.5 \mu \mathrm{g} /$ litre (equivalent to $0.0005 \mathrm{ppm}$ ) [25]. HIV-positive subjects had higher levels of $\mathrm{V}$ compared to their HIV-negative counterparts and these levels were higher than the permissible limit. There has been increased use of vanadium in the fields of science including jet air craft, space technology and the manufacture of ultrafilter glass for prevention of radiation injury as a result of its hardness, resilience and its ability to form alloys [26]. As a result, there is increased Airborne vanadiumbearing articles due to petroleum refining, smelting, welding which have been demonstrated to be associated with hypertension, cancers, dysrhythmia and inflammatory diseases [26]. The massive industrialization and crude oil exploration in the Niger Delta, as mentioned earlier is a clear evidence of huge environmental pollution with health implication of increased exposure to vanadium.

With regards to $\mathrm{Pb}$, there is not much evidence on exposure levels to environmental pollutants among HIV-infected populations. $\mathrm{Pb}$ whose route of administration is either by inhalation, oral or dermal, is a cumulative toxicant which affects multiple systems including haematological, cardiovascular and renal systems [27]. Additionally, $\mathrm{Pb}$ exposure can also be through skin absorption and in Nigeria where leaded gasoline/petrol is sold, this can be very significant [28]. The accepted limit of $\mathrm{Pb}$ in adults is $0-10 \mu \mathrm{g} / \mathrm{dl}[17]$. 
This study demonstrated that subjects with HIV had significantly higher levels of blood lead compared to those without HIV. This elevated level was highest in the patients on the $3 \mathrm{TC}+\mathrm{ZDV}+\mathrm{LPV} / \mathrm{r}$ regimen. Possible explanation to higher blood levels of heavy metals in persons with HIV is that exposures might be similar but HIV infection may interfere with the body's ability to clear these toxins. This is because HIV infection and the use of ART could impair renal and liver functions, which may lead to impaired detoxification and might further influence the clearance of heavy metals from the body [23]. Furthermore, high mean blood levels of $\mathrm{Pb}$ has been established as a toxicant that impairs renal function in exposed subjects in a Port Harcourt study [29]. Additionally, animal studies suggest a decrease in cytochrome $\mathrm{P} 450$ function with $\mathrm{Pb}$ exposure [30]. Lamivudine, the main drug in the regimen is a nucleoside reverse transcriptase inhibitor that is metabolized via the cytochrome P450 and therefore may have its metabolism reduced with increased $\mathrm{Pb}$ exposure. The higher exposure to heavy metals suggested in this study may also play an important role in the development of these chronic diseases among HIV-infected patients.

\section{Limitations to the study}

There was a significant difference between the age of the test group and the control groups. There was no separation between smokers or non-smokers among the study participants hence the influence of smoke could not be established. Despite the limitations, the study was able to generate primary information on the presence of heavy metals in HIV-positive patients in comparison to the HIV-negative persons.

\section{Conflicting interests}

The authors declare no conflicting interests in publishing the paper.

\section{Funding} any agency.

This research received no grant or fund from

\section{REFERENCES}

1. National Agency for then Control of AIDS (NACA). (2015). Federal Republic of Nigeria, Global AIDS Response Country Progress Report.

2. UNAIDS. (2020). Available at https://www.unaids.org/en/resources/presscentre/pr essreleaseandstatementarchive/2019/march/201903 14_nigeria

3. National Agency for the Control of AIDS (NACA). (2020). Available at https://naca.gov.ng/nigeriaprevalence-rate/

4. Federal Ministry of Health (FMOH). (2016). National Guidelines for HIV Prevention, Treatment and Care. National AIDS and STI's Control Programme.
5. Deeks, S.G., Phillips, A.N. (2009). HIV infection, antiretroviral treatment, ageing, and non-AIDS related morbidity. BMJ ;338:a3172

6. Sackoff, J.E., Hanna, D.B., Pfeiffer, M.R, Torian, L.V. (2006). Causes of death among persons with AIDS in the era of highly active antiretroviral therapy: New York City. Ann Intern Med; 145: 397-406.

7. Phillips, A.N., Neaton, J., Lundgren, J.D. (2008). The role of HIV in serious diseases other than AIDS. AIDS; 22: 2409-2418.

8. Mamtani, R., Stern, P., Dawood, I., \& Cheema, S. (2011). Metals and Disease: A Global Primary Health Care Perspective. Journal of Toxicology, Article ID 319136,

9. Moon, S.S. (2013). Association of lead, mercury and cadmium with diabetes in the Korean population: the Korea National Health and Nutrition Examination Survey (KNHANES) 2009 2010. Diabet Med 30: e143-e148. doi:10.1111/dme.12103. PubMed: 23278294

10. Rhee, S.Y., Hwang, Y.C., Woo, J.T., Sinn, D.H., Chin, S.O. (2013). Blood lead is significantly associated with metabolic syndrome in Korean adults: an analysis based on the Korea National Health and Nutrition Examination Survey (KNHANES), 2008. Cardiovasc Diabetol, 12: 9.

11. Satarug, S., Garrett, S.H., Sens, M.A., Sens, D.A. (2011). Cadmium, environmental exposure, and health outcomes. Ciência \& Saúde Coletiva, 16(5): 2587-2602.

12. $\mathrm{Wu}, \mathrm{H}$. (2016). Heavy metals and chelation therapy. Journal of Heavy Metal Toxicity and Disease, 1:1

13. Orisakwe, O.E., Blum, J.L., \& Sujak, S. (2014). Metal pollution in Nigeria: A Biomonitoring update. Journal Health and Pollution; 6. 40-52

14. Li, R. Zhao., L. Li, L. (2017). A Preliminary Study about the Potential Effects of Heavy metals on the Human Male Reproductive Parameters in HIVinfected Populations in China. Biol Trace Elem Res; 180, 39-47.

15. Njoku, C.O., \& Orisakwe, O.E. (2012). Higher blood lead levels in rural than urban pregnant women in Eastern Nigeria. Occup Environ Med; 69(11), pp.850-851.

16. Piot, P., Bartos, M., Ghys, P.D., Walker, N., Schwartländer, B. (2001). The global impact of HIV/AIDS. Nature; 410: 968-973.

17. World Health Organization (WHO). (1996). Trace Elements in Human Nutrition and Health.Geneva: Available from: whqlibdoc.who.int/publications/1996/9241561734_ eng.pdf.

18. Xu, X., Hu, H., Dailey, A.B., Kearney, G., Talbott, E.O, Cook, R.L. (2013). Potential Health Impacts of Heavy Metals on HIV-Infected Population in USA. PLoS ONE, 8(9): e74288. 
19. Emokpae, M.A., Mbonu, I. (2018). Blood levels of some toxic metals in Human Immunodeficiency Virus (HIV) Type 1- Annals of Health Research; Volume 4, Issue No 1: 75-81.

20. Lehmann, I., Sack, U., Lehmann, J. (2011). Metal ions affecting the immune system. Met Ions Life Sci.; 8:157-85

21. Tellez-Plaza, M., Navas-Acien, A., Menke, A., Crainiceanu, C.M., Pastor-Barriuso, R. (2012). Cadmium exposure and all-cause and cardiovascular mortality in the U.S. general population. Environ Health Perspect, 120: 10171022.

22. Ogunfowokan, A.O., Famuyiwa, S.O., Adenuga, A.A., Fatoki, O.S. (2002). Determination of Cadmium and Lead in Urine of some Nigerian Subjects. International Journal of Environmental Health Research, 12: 283-287.

23. Miro, J.M., Cofan, F., Trullas, J.C., Manzardo, C., Cervera, C. (2012). Renal dysfunction in the setting of HIV/AIDS. Curr HIV/AIDS Rep 9:187-199.

24. Jones, M., Núñez, M., Liver toxicity of antiretroviral drugs. (2012). Semin Liver Dis; 32: 167-176.
25. Byrne, A.R., \& Kosta, L. (1978). Vanadium in foods and in human body fluids and tissues. Sci Total Environ, 10(1):17-30.

26. Fortoul, T.I., Rojas-Lemus, M., Rodriguez-Lara, V., Gonzalez-Villalva, A., Ustarroz-Cano, M., Cano-Gutierrez, G. (2014). Overview of environmental and occupational vanadium exposure and associated health outcomes. Journal of Immunotoxicology, 11(1)

27. World Health Organization. Exposure to lead. (2001). A major public health concern. Geneva, (http://www.who.int/ipcs/features/lead..pdf.

28. Galadima, A., Garba, Z.N. (2012). Heavy metal pollution in Nigeria: Causes and Consequences. Elixir Pollution, 45: 7917-7922.

29. Alasia, D., Emem-chioma, P., Wokoma, F., Okojaja, R., Bellgam, H., Iyagba, A. (2009). NDT Plus 2 (suppl 2): ii1733-. Abstracts from the World Congress of Nephrology; May 22-26; Milan, Italy.

30. Lowry, J.A., Pearce, R.E., Gaedigk, A., Venneman, M., Talib, N., Shaw, P., Leeder, J.S and Kearns, G.L. (2012). Lead and its Effects on Cytochromes P450. J Drug Metab Toxicol S5. 